\title{
11-Beta-Hydroxylase Deficient Congenital Adrenal Hyperplasia in a Toddler: Clinical Presentation and Management Challenges in a Developing Country
}

\author{
Onyiriuka $\mathrm{AN}^{1}$, Shaibu $\mathrm{M}^{2}$
}

${ }^{1} \mathrm{Dr}$ Alphonsus N. Onyiriuka, MBBS, FMCPaed. Consultant Paediatrician (Paediatric Endocrinology), ${ }^{2}$ Dr. Moriamo Shaibu, MBBS, MWACP, Senior Registrar in Paediatrics. Both from the Department of Child Health University of Benin Teaching Hospital, PMB 1111, Benin City, Nigeria.

\section{Introduction}

C ongenital adrenal hyperplasia $(\mathrm{CAH})$ due to 11-beta-hydroxylase deficiency is an autosomal recessively inherited disorder of steroidogenesis, characterized biochemically by increased concentrations of deoxycorticosterone, 11 deoxycortisol and delta 4-androstenedione and decreased plasma renin concentration ${ }^{1}$. Clinically it is associated with hypertension and genital ambiguity in affected females ${ }^{1}$. Approximately two-third of patients with 11-beta hydroxylase deficiency become hypertensive and this may take several years ${ }^{2}$. Hypertension is the single clinical feature distinguishing 11-beta-hydroxylase deficiency from 21-hydroxylase deficiency (commonest form of $\mathrm{CAH}$, accounting for $90 \%$ of cases) $)^{3}$. Although 11-beta-hydroxylase deficient $\mathrm{CAH}$ is uncommon, it should be considered in the differential diagnosis of hypertension with virilisation in any prepubecent female.

11-beta-hydroxylase deficiency accounts for approximately $5 \%$ of all cases of $\mathrm{CAH}$ with an estimated incidence of 1 in 100,000 to 250,000 live births $^{2}$. Deficiency of 11-beta-hydroxylase enzyme is due to mutation in the steroid 11-beta-hydroxylase CYP11B1 gene located on chromosome locus 8q21$22^{3}$. In 11-beta-hydroxylase deficient $\mathrm{CAH}$, cortisol and corticosterone are deficient with overproduction of 11-deoxycortisol and 11-deoxycorticosterone. The precursor hormones are shunted into the androgen pathway causing prenatal and postnatal virilisation.

\section{Address for correspondence}

Dr. A.N. Onyiriuka

Department of Child Health

University of Benin Teaching Hospital,

Benin city, Nigeria

E-mail: alpndiony@yahoo.com, didiruka@gmail.com

\begin{abstract}
This paper reported a case of an eighteen-month old Nigerian girl with 11-beta-hydroxylase-deficient congenital adrenal hyperplasia who presented with hypertension and heart failure. The hypertension resolved with steroid therapy. Her blood pressure has remained normal on maintenance prednisolone. The abnormal external genitalia was probably missed at the private hospital where the child was born as it was not mentioned to the parents before discharge on the second day of life. When the child presented at about the age of two months with an enlarged clitoris, she was referred to a paediatric surgeon in another private hospital. It would have been more appropriate to refer her to a paediatric endocrinologist in the nearest tertiary healthcare institution. This case highlights the importance of thorough physical examination of the external genitalia at birth and appropriate referral. The management challenges encountered in the care of this patient included lack of laboratory facilities for diagnosis and monitoring of therapy, non-availability of necessary drugs (oral hydrocortisone) and late presentation.
\end{abstract}

Key words: congenital adrenal hyperplasia, 11-beta-hydroxylase deficiency, hypertension, heart failure.

The accumulation of 11-deoxycorticosterone results in salt and water retention with increased plasma volume and hypertension. Glucocorticoid administration is effective in reversing all the abnormalities and inducing remission ${ }^{3}$.

In developing countries, laboratory facilities for accurate and specific diagnosis of endocrine disorders are lacking, thereby adversely affecting management. Where the facility is available, the cost is prohibitive given the wide-spread poverty in our country.

How to cite this article?

Onyiriuka AN, Shaibu M. 11-Beta-Hydroxylase Deficient Congenital Adrenal Hyperplasia in an Toddler: Clinical Presentation and Management Challenges in a Developing Country. J Nepal Paediatr Soc 2013;33(1):48-51. 
The purpose of this paper is to report a case of 11-beta-hydroxylase deficient $\mathrm{CAH}$ in a Nigerian girl with steroid responsive hypertension and heart failure and promote its awareness among medical personnel.

\section{The Case}

The patient was delivered in a private hospital in Benin City and was discharged home on the second day of life. The health care providers in the private hospital did not mention to the mother that the external genitalia were abnormal. Following discharge from the hospital, the mother also did not notice any abnormality of the external genitalia. At the age of two months, the maternal grandmother noticed a protrusion from the genitals. The patient was then taken to the private hospital where she was born and was referred to another private hospital being managed by a paediatric surgeon. The parents defaulted from follow up in the hope that the protrusion will regress with time. However, the protrusion continued to increase in size and this forced the parents to consult again the paediatric surgeon at his private clinic at the age of 12 months. She had a clitoridectomy at the age of 12 months and was discharged home two weeks later, apparently well. She was not placed on steroid. However, six months later, the patient presented again to the paediatric surgeon with facial swelling and difficulty in breathing which prompted referral to Children's Emergency Room (CHER), University of Benin Teaching Hospital (UBTH), Benin City as a case of bronchopneumonia. Evaluation at the CHER, UBTH revealed no history of maternal ingestion of androgens during pregnancy. She is the younger of two children in the family. The older sibling is a boy. There was no maternal history of hirsutism, genital abnormality or menstrual irregularity. Physical examination revealed a child with an advanced muscular development, a weight of $11.8 \mathrm{~kg}$ and a height of $70 \mathrm{~cm}$. The occipito-frontal circumference was $52 \mathrm{~cm}$. She had facial puffiness, tachypnoea (respiratory rate 72 cycles/ min), dyspnoea and fine basal crepitation. Examination of the cardiovascular system revealed tachycardia (pulse rate 168/min), hypertension (blood pressure $140 / 100 \mathrm{mmHg}$ ) and normal heart sounds. There was no murmur. She had a tender hepatomegaly ( $5 \mathrm{~cm}$ below the right costal margin). Genital examination revealed amputated stump of the clitoris with normal labia majora and minora. The urethral meatus was below the amputated clitoris. The vaginal orifice was well formed. Laboratory investigation revealed normal serum urea and electrolytes values. The results of other investigations are shown in Table 1. A diagnosis of 11-beta-hydroxylase deficient $\mathrm{CAH}$ with heart failure was reached at. The differential diagnosis considered were 21-hydroxylase deficient $\mathrm{CAH}$, 17-hydroxylase deficient $\mathrm{CAH}$, and Cushing syndrome. The patient was commenced on intravenous hydrocortisone which was later changed to oral prednisolone (because of difficulty in procuring oral hydrocortisone). Hydrochlorothiazide therapy was also instituted. Antihypertensive drug was not administered. The hypertension and heart failure resolved without specific antihypertensive therapy.

Table 1: Laboratory results

\begin{tabular}{|l|c|}
\hline Test and normal values & Results \\
\hline $\begin{array}{l}\text { Serum Deoxycorticosterone (DOC): } \\
61-576 \mathrm{nmol} / \mathrm{L}\end{array}$ & $695 \mathrm{nmol} / \mathrm{L}^{*}$ \\
\hline $\begin{array}{l}\text { Serum 11-Deoxycortisol: 0.6-4.6 } \\
\mathrm{nmol} / \mathrm{L}\end{array}$ & $6.1 \mathrm{nmol} / \mathrm{L}^{*}$ \\
\hline $\begin{array}{l}\text { Serum 17-Hydroxyprogesterone: } \\
\text { 0.6-3.0 nmol/L }\end{array}$ & $3.94 \mathrm{nmol} / \mathrm{L}^{*}$ \\
\hline $\begin{array}{l}\text { Serum Dehydroepiandrosterone } \\
\text { sulfate (DHEAS): } 0.1-1.5 \mathrm{mcmol} / \mathrm{L}\end{array}$ & $4.0 \mu \mathrm{mol} / \mathrm{L}$ * \\
\hline $\begin{array}{l}\text { Serum cortisol: } 140-690 \mathrm{nmol} / \mathrm{L} \\
\text { (am) }\end{array}$ & $208 \mathrm{nmol} / \mathrm{L}(\mathrm{am})$ \\
\hline Serum testosterone: $<0.6 \mathrm{ng} / \mathrm{ml}$ & $4.2 \mathrm{ng} / \mathrm{ml}$ * \\
\hline Blood glucose: $4.0-6.7 \mathrm{mmol} / \mathrm{L}$ & $4.6 \mathrm{mmol} / \mathrm{L}$ \\
\hline Buccal smear (for Barr bodies) & $\begin{array}{c}\text { Barr bodies } \\
\text { present }\end{array}$ \\
\hline Abdomino-pelvic ultrasound scan & Normal \\
\hline Chest X-ray & Cardiomegaly \\
\hline
\end{tabular}

*Elevated results

\section{Discussion}

In this patient, the diagnosis of 11-beta-hydroxylasedeficient $\mathrm{CAH}$ with heart failure was based on evidence of virilisation, muscular physique, hypertension, tachycardia, tachypnoea, tender hepatomegaly, and resolution of the hypertension following steroid therapy. The elevated serum levels of 17-hydroxyprogesterone, cardiomegaly seen on chest radiograph and absence of salt wasting were all in support of our diagnosis. One of the tasks in this patient was to determine the genetic sex by distinguishing between a virilized female and a feminized male. This task was successfully accomplished by the karyotype which showed presence of Barr bodies on buccal smear examination and a normal internal female reproductive system (ovaries, fallopian tubes and uterus) on pelvic ultrasonography, consistent with a genetic female. Our diagnosis of 11-betahydroxylase-deficient $\mathrm{CAH}$ was based on the presence of hypertension (which resolved on steroid therapy only) and signs of hyperandrogenism. This diagnostic approach is reinforced by the report of Griqoresen Sido et al, ${ }^{5}$ in which five patients diagnosed clinically as having 11-beta-hydroxylase deficiency on the same clinical basis were later confirmed on molecular analysis to have 11-beta-hydroxylase deficiency. The differential diagnoses include 17-alpha-hydroxylase deficient $\mathrm{CAH}$, 21-hydroxylase-deficient $\mathrm{CAH}$ and Cushing syndrome. Although hypertension is a feature of 17-alphahydroxylase deficient $\mathrm{CAH}$, sexual infantilism rather than 
virilisation is usually seen in females with the condition ${ }^{2}$. In this patient, there was virilisation making 17-alphahydroxylase deficient CAH less likely. Epidemiologically, 21-hydroxylase-deficient $\mathrm{CAH}$ accounts for about $90 \%$ of all cases of $\mathrm{CAH}^{2}$ and was therefore, considered one of the differential diagnoses. Hypertension is not a usual clinical feature of 21-hydroxylase-deficient $\mathrm{CAH}$, therefore its presence in the index patient made the diagnosis of 21-hydroxylase deficiency less likely. The normal values of serum potassium and bicarbonate obtained in this patient negated the diagnosis of 21-hydroxlase deficiency. Although Cushing syndrome may be associated with hypertension and virilisation, particularly if it is due to adrenal carcinoma, ${ }^{3}$ absence of cushingoid facies and the good response of the hypertension to steroid therapy negated its diagnosis. In addition, there was no evidence of weight loss both historically and on physical examination. The absence of abdominal mass on physical examination which was further confirmed by ultrasonography and the elevated serum DHEAS were all against the diagnosis of Cushing Syndrome.

In this patient, hypertension and heart failure were observed. This is not surprising as similar observation has been documented in previous studies among patients with 11-beta-hydroxylase- deficient $\mathrm{CAH}^{6,7,8}$. The hypertension is thought to be due to the accumulation of deoxycorticosterone resulting in sodium and water retention, increased plasma volume which in turn, causes hypertension ${ }^{3}$. As in previous reports ${ }^{1,7,8}$, glucocorticoid therapy was effective in reversing all the abnormalities and inducing remission in the index patient. The control of hypertension with glucocorticoid therapy is as a result of the feedback inhibition of the hypothalamus and the pituitary gland, resulting in a reduction in $\mathrm{ACTH}$ secretion. As a consequence, the production of deoxycorticosterone as well as androgens is reduced, lowering blood pressure and preventing further virilization. The virilization and advanced muscular development in our patient were as a result of cortisol precursor hormones which were shunted into the androgenic pathway causing prenatal and postnatal virilization ${ }^{3}$.

The index patient illustrated some of the management challenges encountered in developing countries among children with an aberrant external genitalia. Such challenges include lack of laboratory facilities for diagnosis and monitoring of therapy, nonavailability of necessary drugs and late presentation with its sequelae. First, the aberrant external genitalia of this patient were missed at the health facility where the child was born, suggesting inadequate examination of the external genitalia by the healthcare providers. Similar observation has been documented in previous studies $^{9,10,11}$. Following the discovery at home of the enlarged clitoris and the subsequent presentation at the private hospital where the child was born, the physician referred the patient to the paediatric surgeon rather than the paediatric endocrinologist. This decision resulted in continued exposure of the child to high levels of androgenic hormones, resulting in further virilisation postnatally. Had the patient been referred to the paediatric endocrionologist initially, therapeutic measures to control the continued accumulation of androgenic hormones would have been instituted, preventing further postnatal virilization. The long delay (9 months) before medical help was sought even after the enlarged clitoris was discovered by the maternal grandmother compounded the situation. The mother had hoped that with time, the enlarged clitoris will regress spontaneously, illustrating the gross lack of disease awareness in our local community. Similar observation concerning poor awareness has been reported in a previous study in Benin City ${ }^{11}$. The potential consequences of late presentation include precocious puberty and short stature in adulthood. Lack of facility for definitive diagnosis, such as determination of specific enzyme defect, and even biochemical follow up to monitor therapy is very common in most developing countries, including Nigeria ${ }^{4}$. Where the facility for hormone assay is available, the cost is prohibitive. The healthcare providers paid for most of the investigation performed in this patient. Procurement of oral hydrocortisone (drug of choice) was very difficult. Most pharmacy stores in Benin City do not stock oral hydrocortisone, forcing us to use prednisolone (which is less effective) as an alternative.

\section{Conclusion}

The external genitalia of all neonates should be thoroughly examined at birth and the patient should be referred appropriately as indicated by their clinical condition. Greater attention should be paid to the National Health Insurance Scheme to reduce out-ofpocket payment for healthcare, at least for children.

\section{References}

1. Nimkarn S, New MI. Steroid 11-beta-hydroxylase deficient congenital adrenal hyperplasia. Trends Endocrinol Metab 2008;19(3):96-99.

2. White PC. Congenital adrenal hyperplasia and related disorders. In: Kliegman RM, Behrman RE, Jenson HB, Stanton BF eds. Nelson Textbook of Pediatrics $18^{\text {th }}$ ed. Philadelphia, Saunders Elsevier, 2007: 2360-2368.

3. Raghupathy P. Disorders of adrenocortical biosynthesis. In: Parthasarathy A ed. IAP Textbook of Pediatrics, $4^{\text {th }}$ ed. New Delhi, Jaypee Brothers Medical Publishers Ltd 2009: 951-955. 
4. Famuyiwa OO. Problems and challenges in the practice of endocrinology in a developing country An overview. Nig Med Pract 1990;20(1):3-6.

5. Griqoresen Sido A, Weber MM, Griqoresen Sido P, Claumeyers S, Heirich U, Schulze G. 21-hydroxylase and 11-beta- hydroxylase mutations in Romanian patients with classic congenital adrenal hyperplasia. J Clin Endocrinol Metab 2005;90:5769-773.

6. Cerame BI, New MI. Hormonal hypertension in children: 11 beta-hydroxylase deficiency and apparent mineralocorticoid excess. J Pediatr Endocrinol Metab 2000;13(3):1537-547

7. Al Jarallah AS. Reversible cardiomyopathy caused by an uncommon form of congenital adrenal hyperplasia. Pediatr Cardiol 2004;25(6):675-76.
8. Isiawe AR, Ekpbegh CO, Fasanmade OA, Ohwovoriole AE. Steroid responsive hypertension secondary to 11-beta-hydroxylase deficiency - a case report. West Afr J Med 2008;27(3):182-85.

9. Osifo OD, Nwanshili JN. Congenital adrenal hyperplasia: the challenges of management in a developing country. Afr J Urol 2008;14:138-42.

10. Ozoemena OF, Mbah AU. The prevalence pattern of external male genitalia defects among secondary school students in Enugu State of Nigeria. Niger $J$ Clin Pract 2007;10:120-25.

11. Osifo OD, Amusan TI. Female children with ambiguous genitalia in awareness-poor subregion. Afr J Reprod Health 2009;13(4):129-36. 